\title{
تشكيلية القصيدة البصرية في شعر فاضل العزاوي صاعدا حتى الينبوع انموذجا
}

\section{م.د.شاكر عجيل صاحي الهاشمي}

كلية الآداب / جامعة واسط

توطئة:

تسعى هذه الدراسة إلى معرفة السبل البصرية التي تجسد هويـة الخطـاب الشعري لدى الثـاعر فاضل العزاوي،

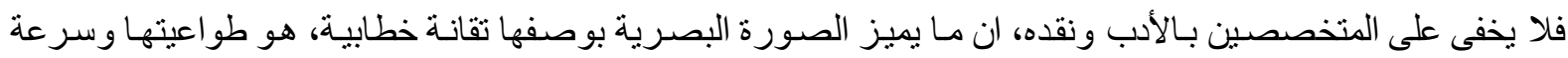

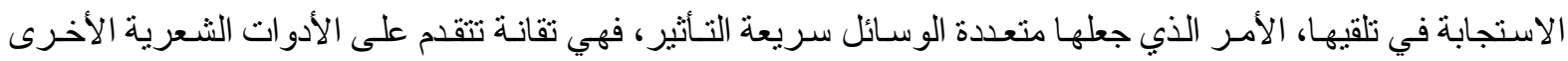

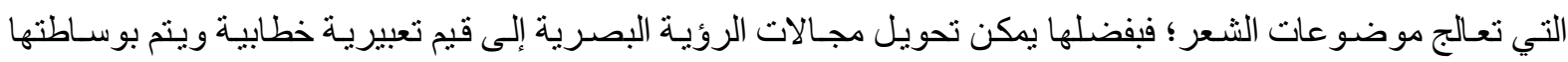

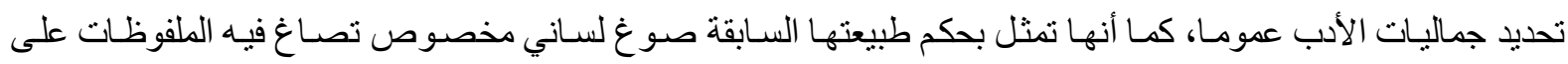
وفق أعراف بنائية جديدة تتشكل المعاني فيه تشكلا مختلفا يفضي بها إلى تشكيل مرئي مغاير ( ' تكثف عنف عن عائدات

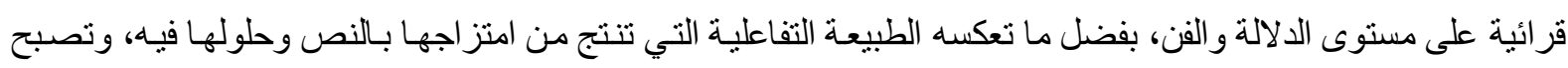

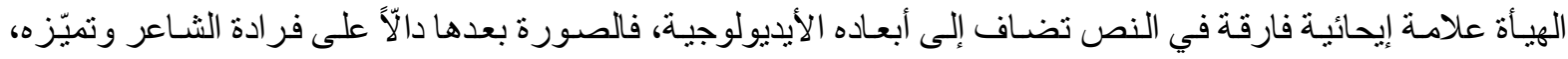

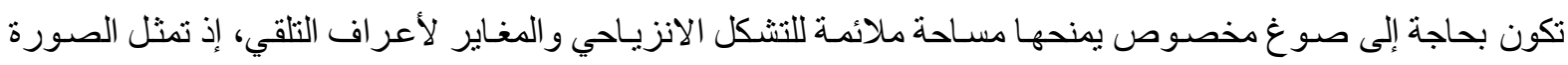

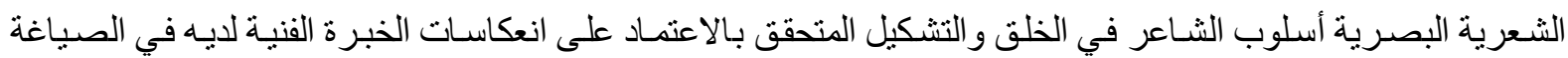

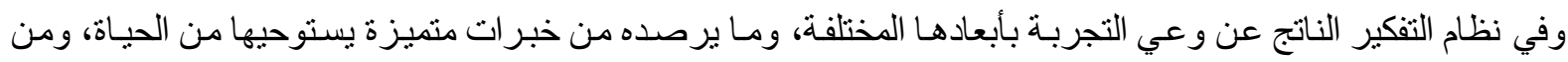

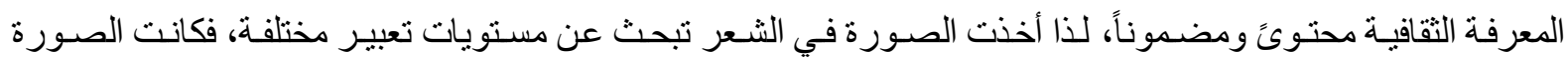
المرئية احد هذه المستويات التي تميزت بمستوى أبعدَ في المدى التـأويلي ممـا جعلها تتسم بفاعليتها المميزة في إسناد

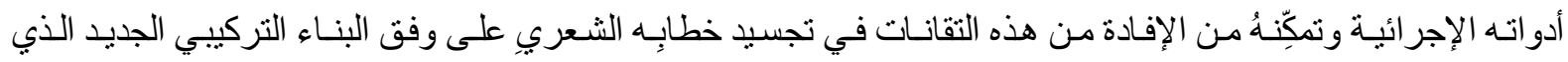
يجسد له التعادلية في مستوياته المختلفة، لتتكثف المسافة التصويرية ببعديها الفني والايحائي(؟). ويبدو أن المسألة أصبحت ضرورية إلى تقليل الهوة التي تفصل الثـعر عن الأجناس الأدبية الأخرى، فـالقصيدة

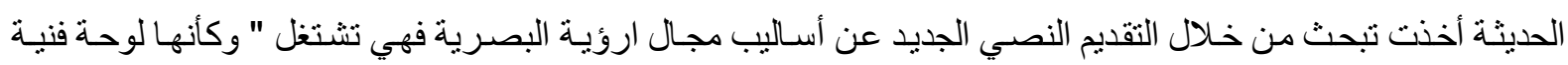

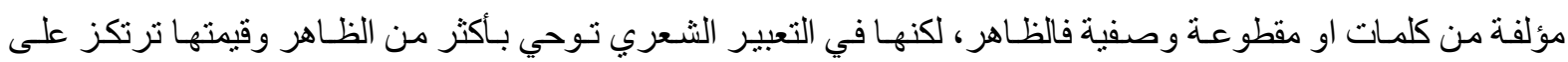

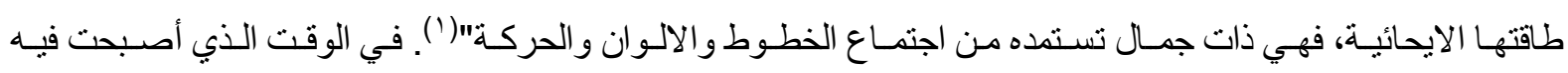

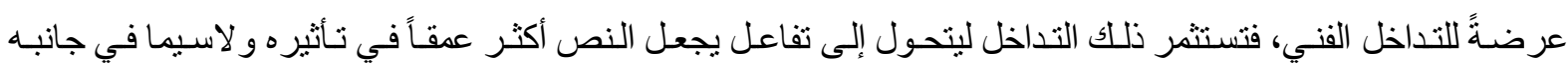

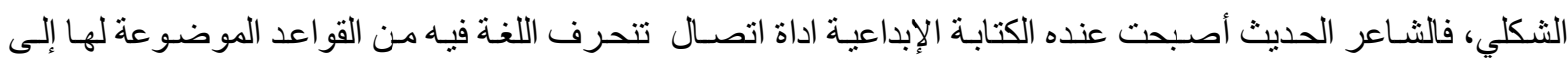
مستوى جديد توظف فيه مجالات الرؤية البصرية، والمتلقي أصبح يعي هذه الكيفية ويتفاعل معها في إنتاج قر اءة جديدة على وفق هذا التلقي.

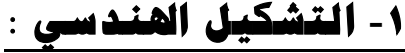

يمكن أن نقف عند مفهوم الصـورة في هذا البـاب على أنها تمثنل عنصـر اً جو هريـاً فيه، فقد نولدت في عمليـة

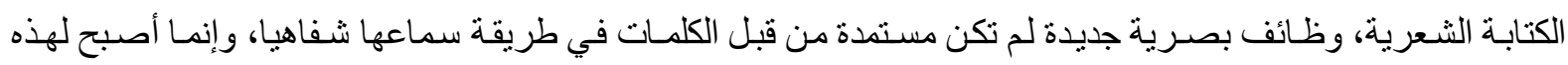

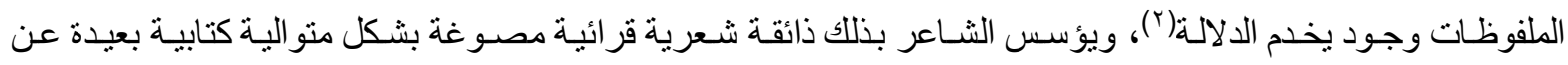
الثفاهية المسمو عة، من خلال مناز عة لا هو ادة فيها بين الثفاهي و الكتابي (ّ)، ويتأتى نجاح التشكيل في القصيدة الحديثة 
المرئية من خلال العبقرية الهندسية لصياغات الثـاعر لملفوظاته ومعرفته في التجهز لانثـاء أسـاليب جديدة للروئية تعلي من امكانات هذه الملفوظات فالشاعر في اشتخالاته يعمل على ضبط التشكيل الشـعري المختلف عبر التحو لات ذات التأثير

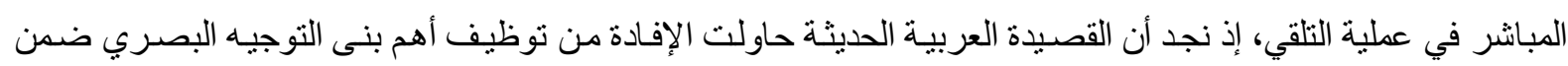

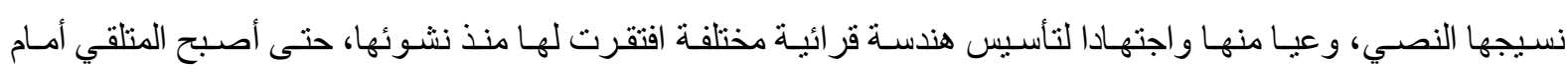

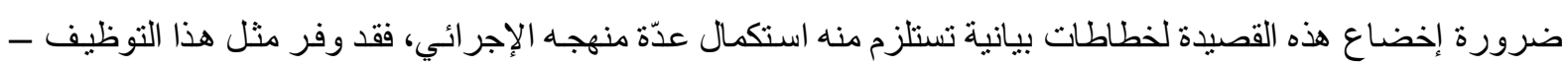

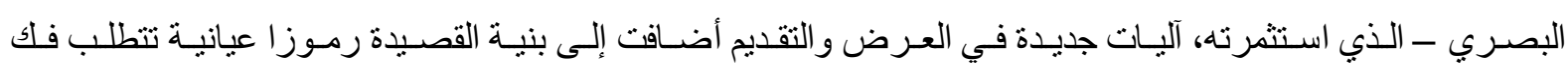

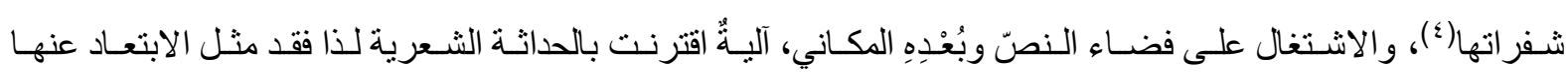

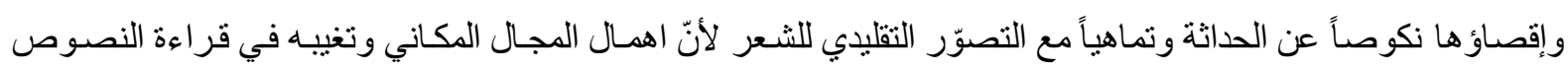

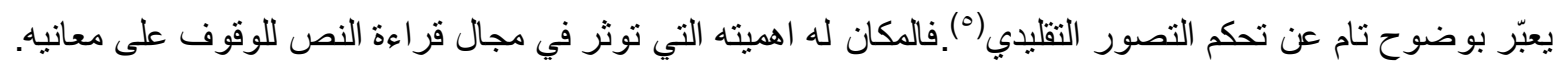

ومن امثلة هذا النوع من التجسيد قصيدة (( القصيدة التي تأكل نفسها)):

$$
\begin{aligned}
& \text { "انهم لا يجيئون، لا في القصائد أو كلمات السفر }
\end{aligned}
$$

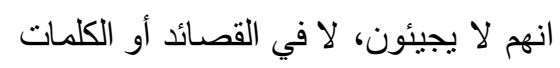

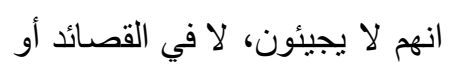

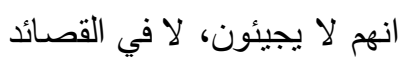

$$
\begin{aligned}
& \text { انهم لا يجيئون، لا في لائون، لاني }
\end{aligned}
$$

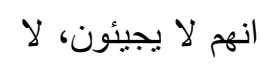

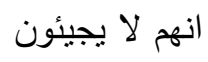

$$
\begin{aligned}
& \text { انهم لانه لان } \\
& \text { انهم" (') (1) }
\end{aligned}
$$

نلحظ أن الثـاعر في هذه القصيدة قد أوكل جز عاً مهمـاً من سياقها المسلولي إلى سياقها الرؤيوي الثكلي، فهو

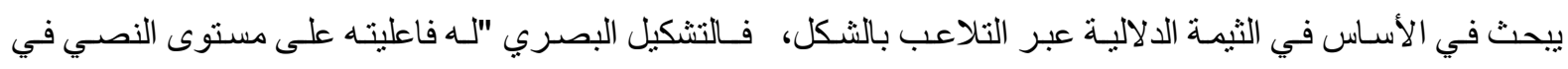

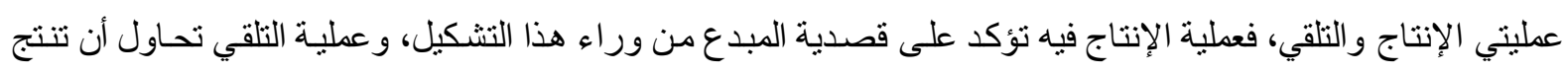

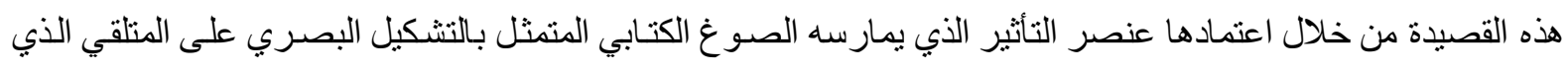

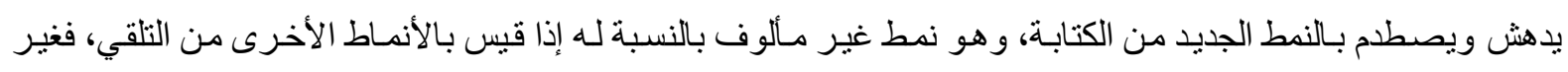

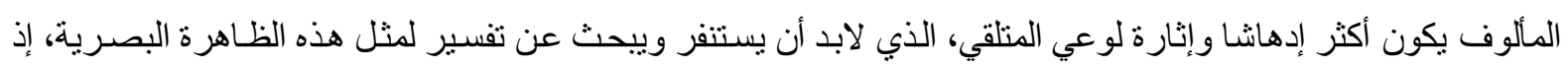

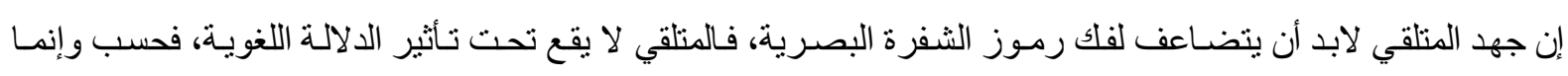

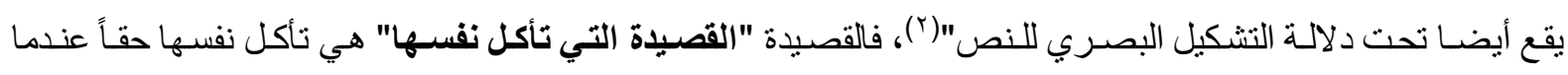

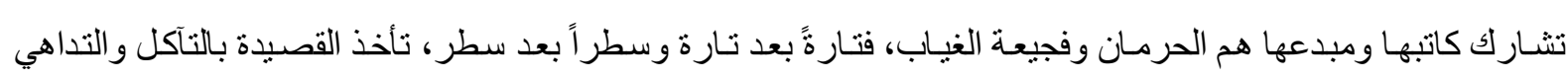

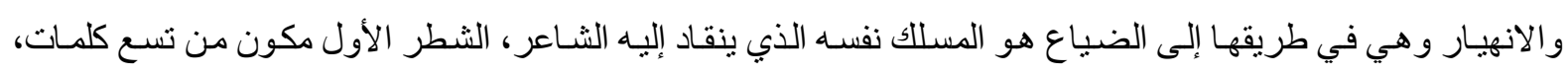

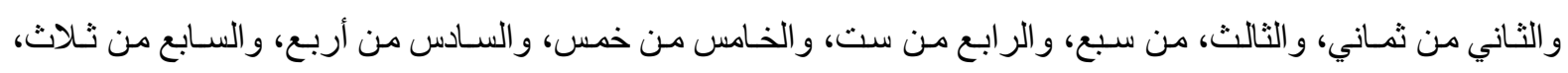

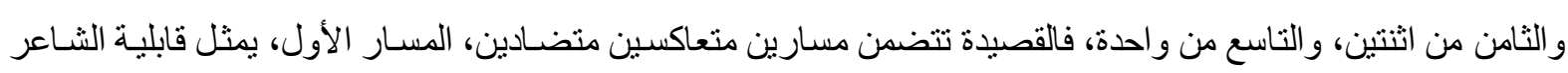
على الحديث والكلام و الكتابة و التفاعل الاجتمـاعي و الوجداني المتمثل بالأسطر الشعرية، والمسـار الثاني ينمثل في تخلي 
القصيدة عن أجز ائها سطر اً بعد سطر، وكأن الشاعر ير اهن على البقاء والتحدي بالاستعانة بالشعر، ففي كل سطر ينزف ر. كلمة لكنه يحاول أن يو اصل حتى وإن كان ذلك على حساب الصمت و السكوت.

ومن القصـائد الأخـر التـي تتضـمن أبعـاداً جماليـة شكلية، قصـيدته (لـــاذا؟)، إذ يتلاعب الثــاعر في البنيـة

الثكلية للقصيدة غاية في ذاته، ليقول:

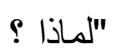

ل ماذا ؟ لماذا ؟

ل لماذا ؟ لماذا ؟ لماذا ؟

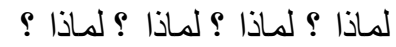

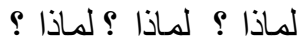

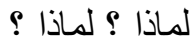

لماذا؟

سقطت وأنت السماء تظلل وجه الضحية ؟"(')

يجسد الثـاعر في هذا النص ثقافتـه الظـاهر اتيـة الرؤيويـة لييني لنـا النص على وفق هيـأة شـعرية تتكامـل

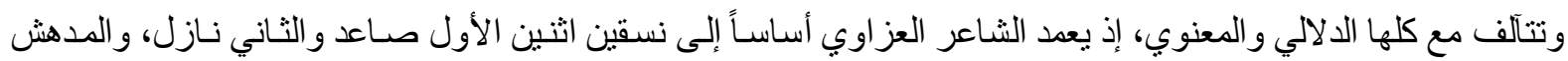

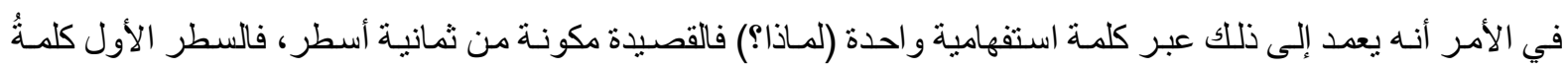

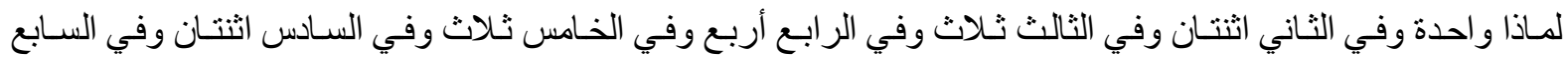

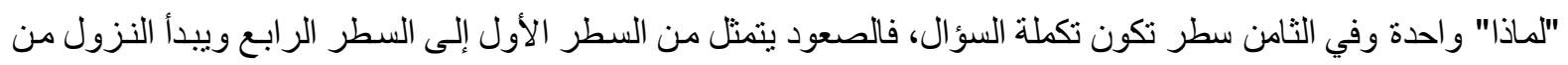

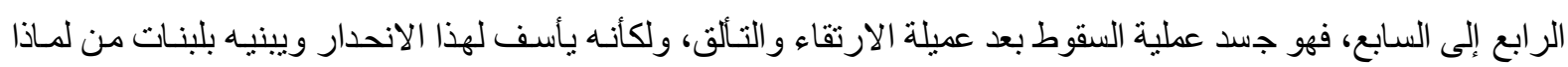

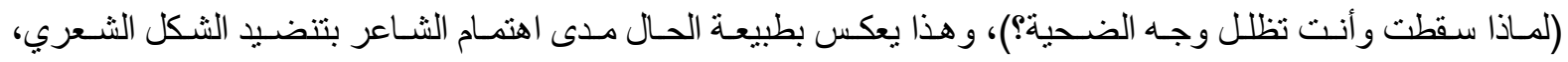
وبر اعته في جعل الشكل يبدو بحالة يمكن لها أن تقوم بإنتاج الدلالة.

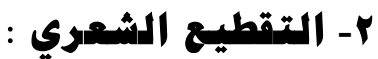

تتفاوت الاستعمالات و التوظيفات الثكلية التي يتبناهـا الثـعر اء في شعرهم، فليس كل تقطيع يمـارس في عملية

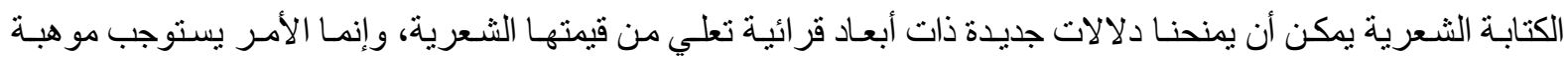

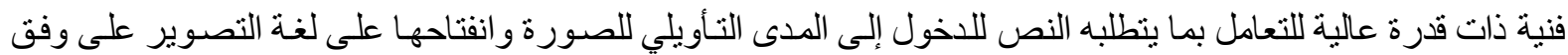

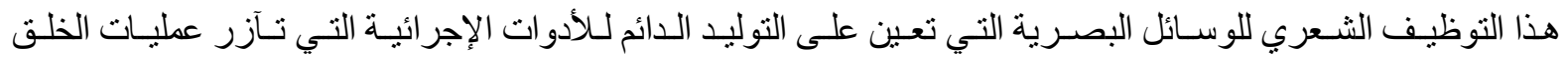

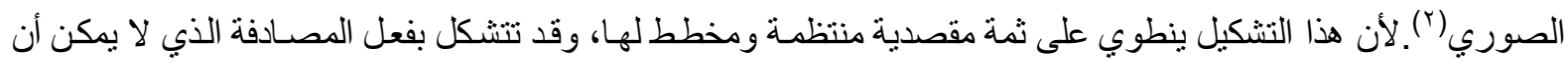

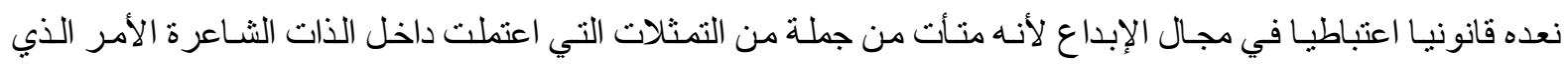

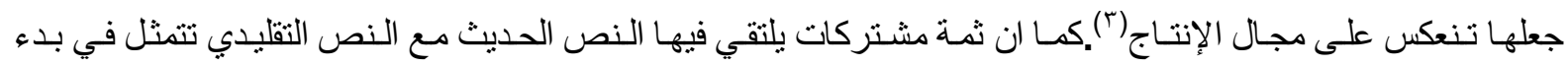

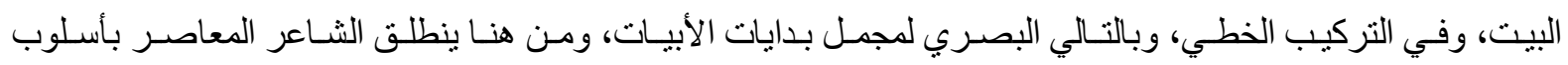

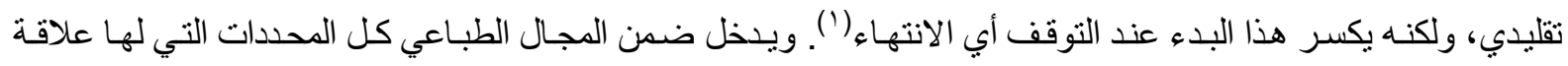
بـالنصنّ وطريقة عرضـه على الصفحة البيضـاء، بدءاً بحجم الكتاب مرور اً بـالورق ونو عيتهـ ومختلف التقنيات الطباعيـة 
التي يوظّقها الثـاعر في تنظيم صفحته من فراغات وحواشِ و ألوان انتهاءً بـالغلاف ومـا يحويـه من رسوم وألوان تسهم في

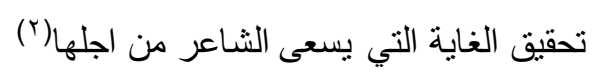

ويوظف العزاوي في كثيرٍ من قصائده تلك التمثلات الثكلية ومن أبرز تلك القصائد قصيدة "مسمار:"

$$
\begin{aligned}
& \text { "آخذ مسماراً († انجات) } \\
& \text { أجلب من سوق الحدادين } \\
& \text { مطرقة } \\
& \text { و ادقه في جسدي } \\
& \text { بهدوء } \\
& \text { بهدوء } \\
& \text { بهاو } \\
& \text { يجتمع المارةُُ حولي في الثشارع } \\
& \text { - من هذا المصلوب؟ }
\end{aligned}
$$

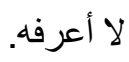

$$
\begin{aligned}
& \text { آخذُ مسمارًا } \\
& \text { بهاو } \\
& \text { بهدو } \\
& \text { أشعلُ نار اً فيَّ وابقى ملتهباً } \\
& \text { يذبل } \\
& \text { وجهي } \\
& \text { يفنى } \\
& \text { جسدي } \\
& \text { كل الأشياء تموت } \\
& \text { بهدوء } \\
& \text { بهدوء } \\
& \text { بعد سنين في الرمل برى طفلٌ مسمار اً } \\
& \text { يحمله بعد لبن } \\
& \text { بهدوء } \\
& \text { بهدوء" (1) }
\end{aligned}
$$

يبدأ العز اوي قصيدته هذه التي بناهـا على وفق موسيقى تفاعلية هادئة بتفاعل آخر كبير يجمع مـا بين الرافد

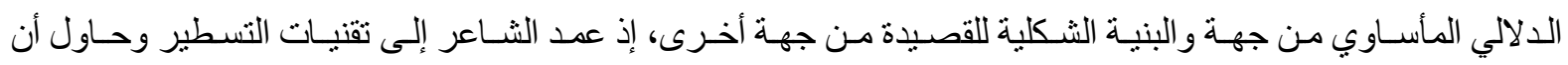

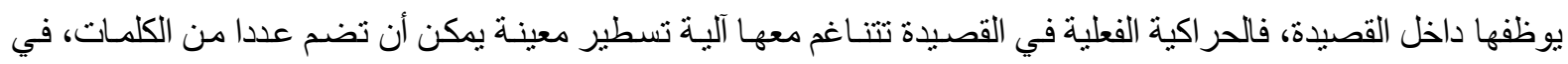
حين أن الدراما الهادئة و الكلمات التي توحي بالهدو هو والسكينة فإنها تجسد الهدوء عبر آليـة التسطير الثكلية عندما يبدأ 
بإفراد الكلمات (هلوء، هلوء، هلوء) و هذا يعكس الثقافة الثكلية التي جسدت رؤيـا الثـاعر للحياة من حوله، فـ "التناعب

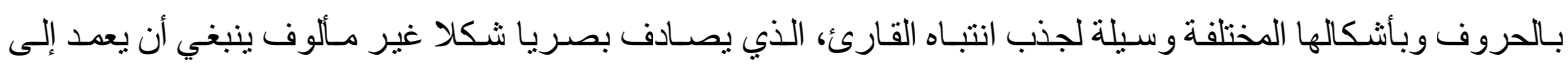
استرجاعه واستقباله استقبالا ناتجا عن التشويش البصري، الذي يؤدي إلى تثـويش نفسية القارئ الذي عليه أن يتو اصل مع النص الشعري"(؟)، كما أنه صادق على أن القصيدة تحدثت وتكلمت عبر أكثر من شق، في البنية والحكاية.

ومن القصائد الأخرى التي يتبنى الثاعر فيها طابعه الثكلي وفلسفته الأيقونية، قصيدة (أسلاك شائكة)، إذ يقول

$$
\text { منتقل }
$$

للبحر يكون سياجا على خاصرة الأطفال

هكذا

نطفى

شار عا بعد آخر

هكذا

نفتح

قلب السمكة

و وكذا

دائما: حديقة، نوم، و وأسلاك شائكة

$$
\text { كلب كلى الربيع }
$$

تظهر إرادة الثاعر في هذه القصيدة عبر إمكانيته الواضحة في توظيف شكلها وظاهر هـا لينسجم مع مضمونها

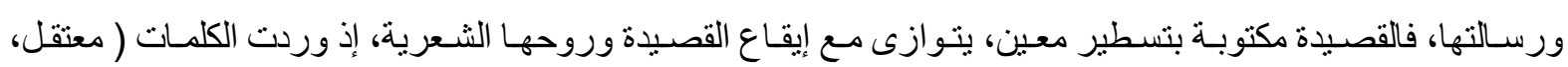
نشعل، شموعا، هكذا، نطفى، هكذا، قلب السمكة، وهكذا، في الغابة، على الربيع) أتت هذه الكلمـات مقطعـة لكل واحدة

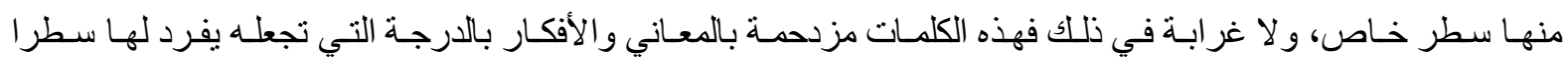

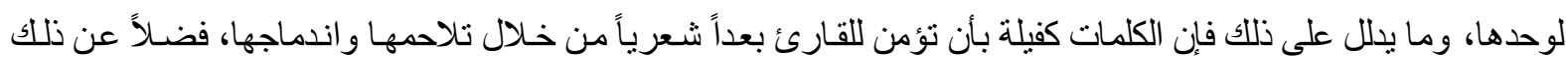

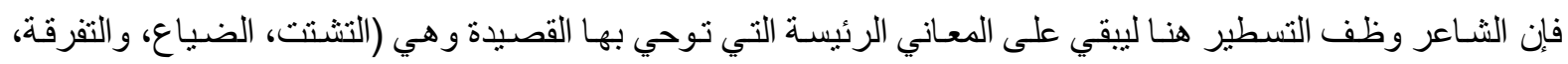

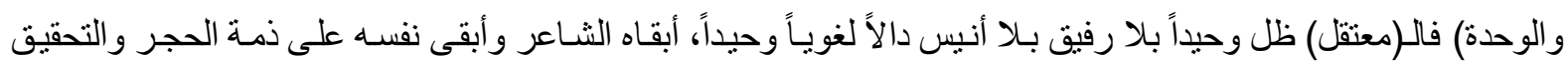

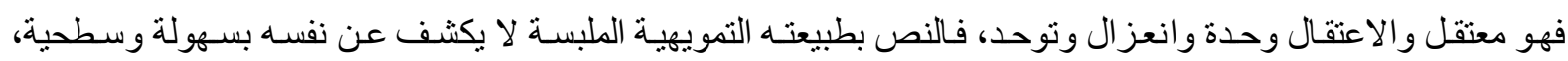

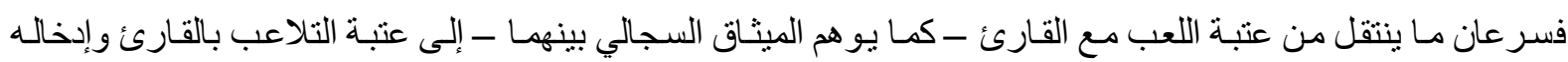

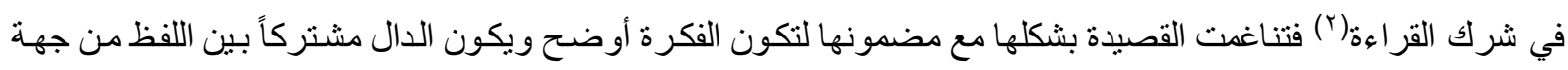
ورسم القصيدة من جهة ثانية، ليصل المدلول إلى أوج صوره التعبيرية. 
علامـات الترقيم احد أهم مجـالات كتابة القصبدة البصرية "فلالترقيم بتشكل من علامـات لا اثر لها في سلسـلة

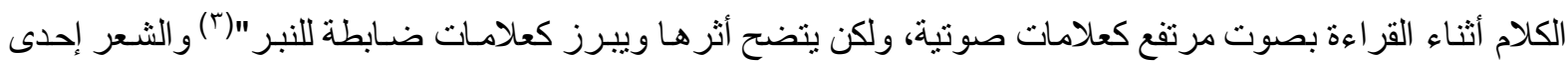

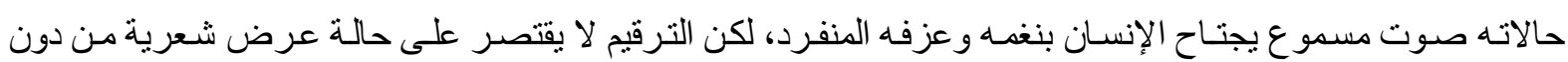

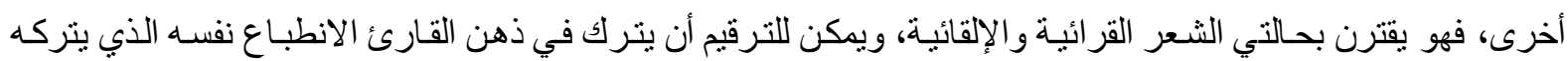

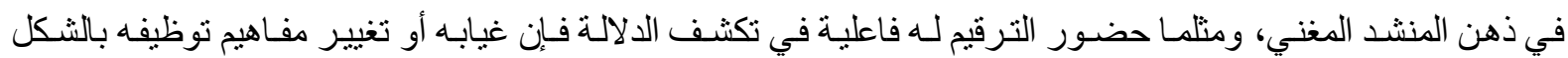
الصحيح ، كثير ا ما نجده فاعلا في كثف الدلالة، أو إنتاج معنى نقيض(')، ويأتي فاضل العزاوي من بين الشعراء الذين تتبهوا إلى تللك المفارقات الدلالية التي ينركها الترقيم في القصيدة، بل إنه أقر بحاجة القصيدة الحديثة والقصيدة بشكل عام إلى الترقيم لأن الثـعر اضطر اب واحتر اق مسلولي مستمر ، وعلامـات الترقيم ليست إلا دليلا و اضحاً على عدم اعتياديـة هذا الخطاب، يقول الشاعر العزاوي:

"كم مرة يمكن للصحر اءِ أن يحتلها الأعداءُ حتى تحملَ السلاح !

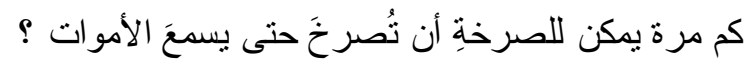

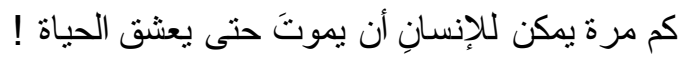

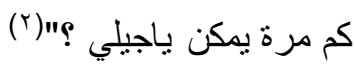

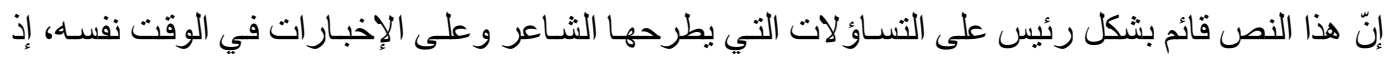

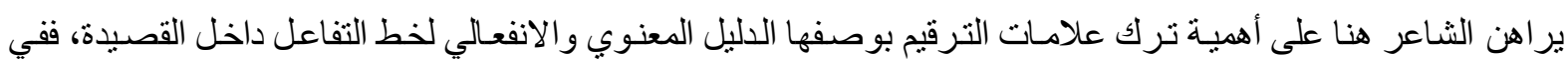
السطر الأول "كم مرة بمكن للصحر اء" فإنه ينرك علامـة التعجب للتنليل على الاستغر اب من مفارقة الحرب و الصحراء والأعداء، لكنه يتسـاءل في السطر الثاني "كم مـرة يمكن للصرخة أن تصر خ حتى يسمع الأموات؟ "فهنا يستفهم لأنـه يكثف للقارئ أنه لم يكن ليعرف الإجابة وكأنه يستتجد بمن يقرأ النص ويطلع عليه، و علامـات الترقيم هنـا ليست إلا كثفاً

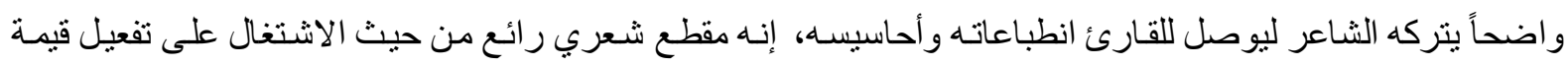

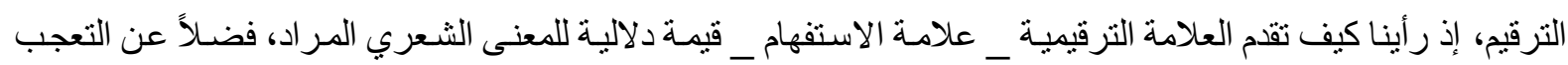
الذي ظل مسانداً للمعنى المُستنفهم عنه هنا في هذا المقطع. ومن القصائد الأخر التي تجسد تلك الحالة من التوظيف لعلامات الترقيم قصيدة "أسئلة:

$$
\begin{aligned}
& \text { "من الذي يقتلُ هذا الجسدُ ـ الصحر اء؟ } \\
& \text { الليل في هبوطه المنحرف؟ }
\end{aligned}
$$

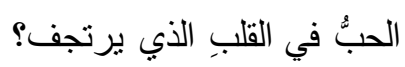

$$
\begin{aligned}
& \text { الظل ؟ الأسماء؟ } \\
& \text { من الذي يقتل هذا الجسد ـ السماء؟ } \\
& \text { القوس؟ } \\
& \text { لاشيء إلا القوس } \\
& \text { لاشيء حتى القوس"(') }
\end{aligned}
$$




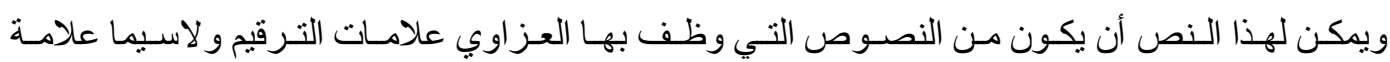

الاستفهام، إذ إن هذه العلامـات كانت جز ءا من بنـاء النص المتقدم فقد حققت تأثير ا بـارزا من جهة إنتاج الدلالة لكونها

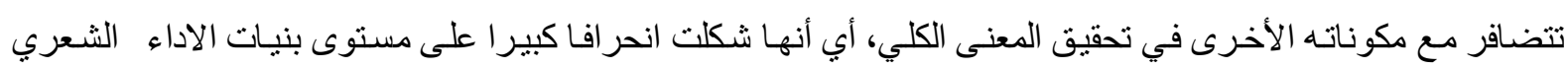

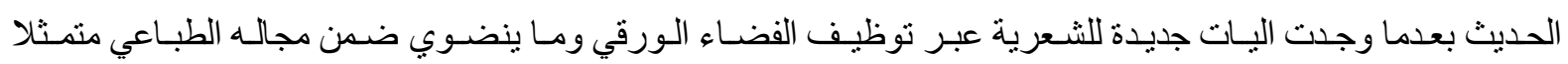

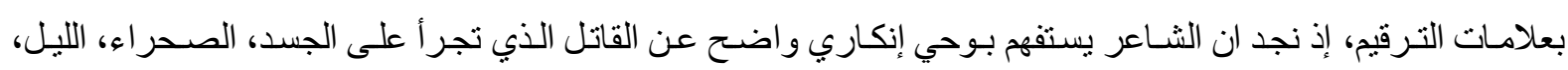

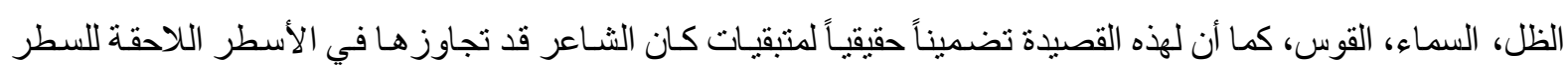
الأول من النص فهو لم يذكر بطبيعة الحسال السؤال (من الذي قتل؟) لكنه يستوفي فاعليته في الأسطر اللاحقة لـه ليظل

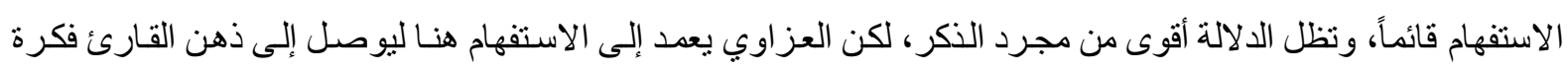

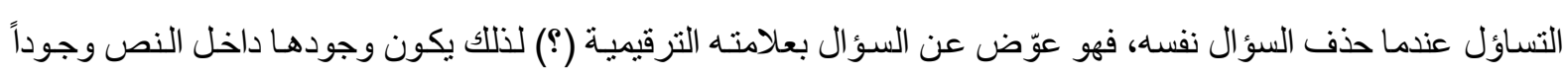
مفصلاً وضرورياً من الناحية الدلالية من جهة والبنيوية من جهةٍ ثنانية.

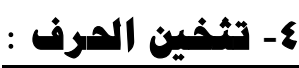

ان الشـاعر في هذا المنظور سـى إلى أن يعدّ "الثعر الحديث شـعر اً قرائياً لا سماعياً وأن القصيدة الحديثة لا

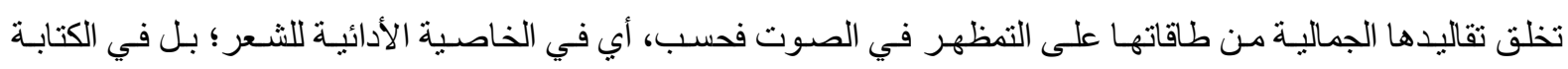

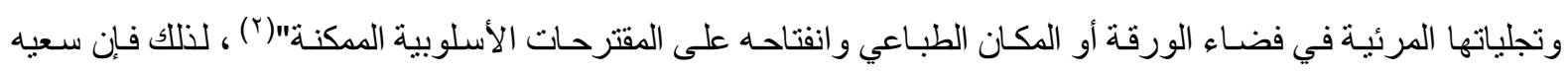

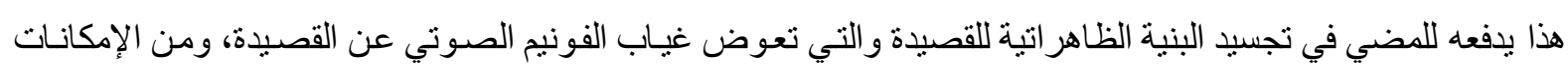

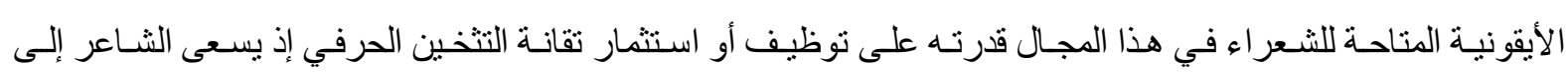
توظيف تلك التقانة في قصيدته (هلو فاضل العزاوي) تلك القصيدة الدرامية التي تعدد إلى الحوار بشكل كبير:

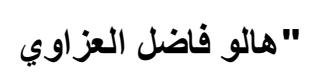

هذا أنا أتحلث اليك من جرف الازمنة

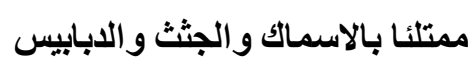
حيث لا يوجد نفق.

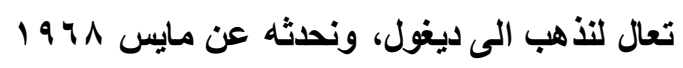
تعال لنذهب الى جنر الات اليونان ونسمع موسيقى زوريا تعال لنذهب الى ناسيتيون وهو يأكل الثيوعيين تعال لنذهب الى عمان وننظر في كل العو اصم العربية تعال لنذهب اللى سجن ما، ونحثثه عن كل السجون تعال لنذهب الى لا مكان"(') في هذه القصيدة هناك دافع كبير ورغبة عارمة في تغيير مـا هو كائن إلى مـا هو مككن إذ يؤكد عامل التنخين

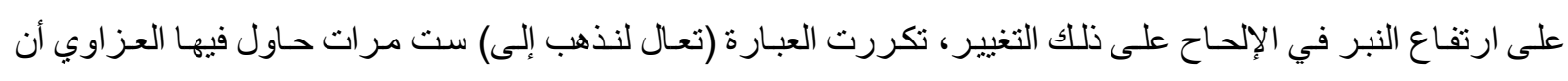

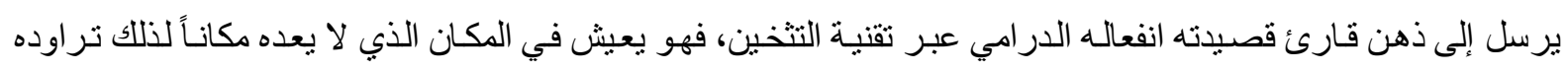

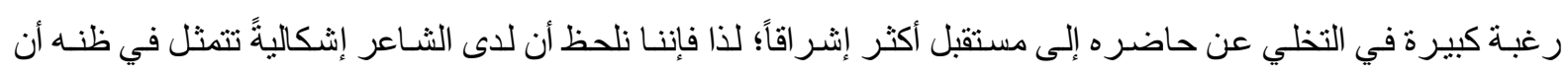

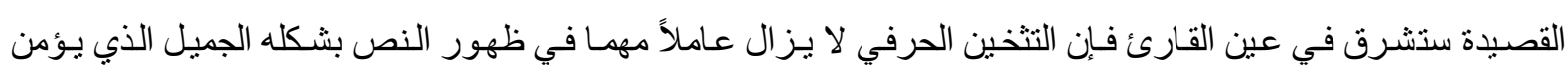


للقـارئ القر اءة الو اضحة الجليـة، فكل متلقي للنص المكتوب يجسد، في حقبقته، أحد المعاني المكنـة للنص المقروء(؟) وفي ذلك انعكاس لرغبات دلالية كثيرة تعدد الثاعر التعبير عنها من منطلق مكاني بحت، إيماناً بالطبران نحو اللامكان. ومن قصائد العز اوي الأخر قصيدته (وعبرنـا الطريق إلى الجاهلية) التي يوظف فيها التخين في جانب من

$$
\begin{aligned}
& \text { القصيدة من دون جانبها الآخر: } \\
& \text { "و عبرنا الطريق الى الجاهلية } \\
& \text { حيث مدت الينا السهوب الجمبلة } \\
& \text { لوحة العشب في واحة بستظل بها الهاربون } \\
& \text { فوجدنا الجنود يبيعون ارقامهم لليهود } \\
& \text { ور أينا امرأ القيس يبكي وحيدا ، صرخت وحيدا: } \\
& \text { خرجت من الايام بيني ويينها } \\
& \text { مضيق الى المجهول يعبر ممطر الهر } \\
& \text { وجبت الصحارى بالدموع تخضبت } \\
& \text { وبيت ملوك الفجر اصبح مقفرا } \\
& \text { بكى صاحبي لما رأى الدرب دونه }
\end{aligned}
$$

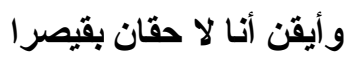

$$
\begin{aligned}
& \text { فقلت له: لا تبك عينك و إنما }
\end{aligned}
$$

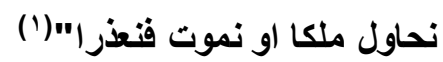

في هذا النص كذلك تتضح فكرة التثنين الحرفي إذ يوظفهـا العز اوي ليكمل وحي القصيدة لكن بدافعيـة وفاعلية أكبر، ويمكن للقارئ أن يستشف من النص أنه مكون من نصفين أمسا النصف الأول فإنه منمثل بتمهيد القصبدة

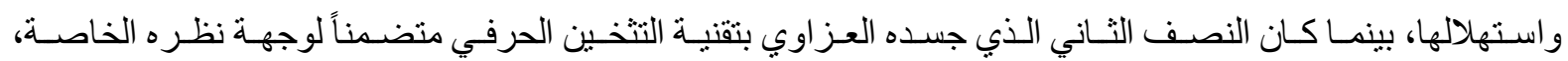

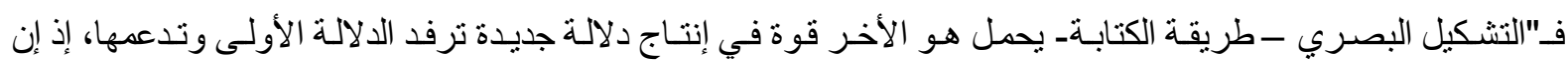

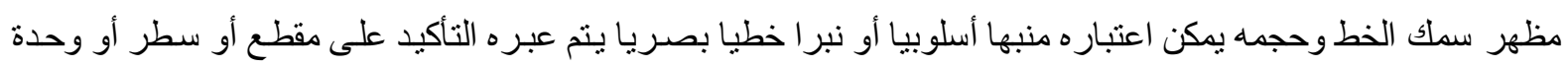

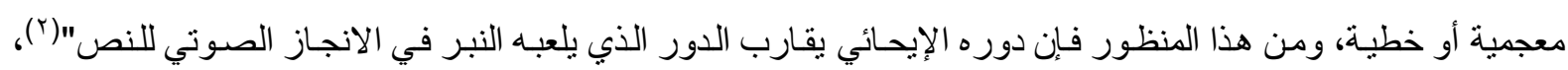
و بنللك فإنه يتمكن من التوغل إلى حساسية المرئي عند القارئ، كما ير اهن الثـاعر على التراث في هذه القصيدة ليقتطف

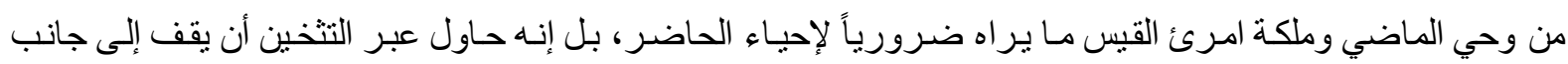
حاضره بعد أن وجده يتلكأ ويموت ويضمحل، فهي إذن أسـاليب تقانية يتعمدها الثـاعر الحديث ليبتكر لقارئهه أفانينَ جديدةً في التلقي والقراءة.

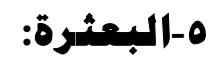

يعد الشكل الكتابي من ابرز بنيات النصوص الشعرية الحديثة، فدلالتها تتشكل من خـلال مكوناته البصرية فـ

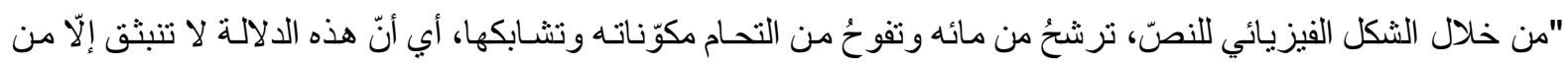
خلال علاقة التجسيد المتبادلة بين رؤيا النصّ وبين بنيته اللغوية، وهذه العلاقة قد تمضي إلى نهايتها القصوى حين التين تتبادل

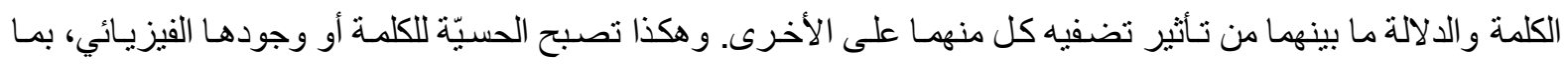

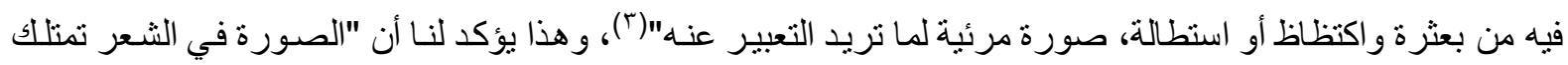


قوة خارقة قادرة على زعز عة تماسك المادة عند الدخول في صومعة التجربـة، حتى تصبح رسما بالكلمات كمـا لو كانت

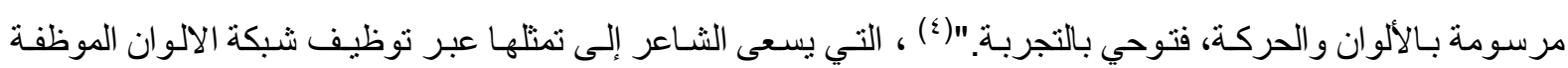

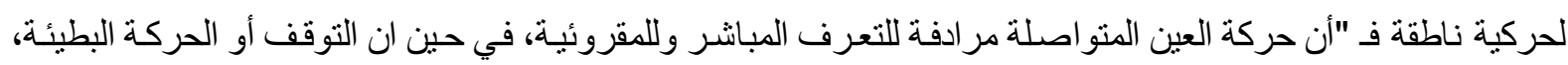

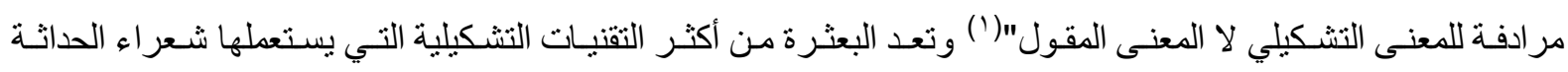
ومنهم فاضل العزاوي، إذ يقول في قصيدة (الريح، الريح، الريح):

$$
\begin{aligned}
& \text { "بين العا } \\
& \text { لم والكلما } \\
& \text { ت: }
\end{aligned}
$$

هجرة اسما

ك)

وقصائد ما

وصلاة

الكلمات سيو

J

فلنو

ققها

ولنبدأ فصلا آ

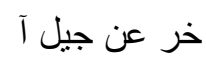

خر، يولد من سهل رما

دِ إِ من ربوة تفا

حوٍ

جو

ر)

يا اصوات الجيل العاثر

يا مكتشف العري بقلب الثائر

اسرع اسر عبي عبر الغابات المذعورة

واجعل من قدري اسطورة

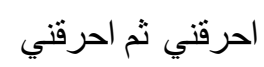

فوق روابي عامورة

واحفر فوق جبيني شارة

أسدل وأنس، اسدل فوق البحر ستارة

فأنا

اكره ان اسقط في معركة الناريخ الاولى 


$$
\begin{aligned}
& \text { ها إن الانسا } \\
& \text { يحمل معناه يموت كأبيّ مسيح } \\
& \text { الريح الريح الريح } \\
& \text { لن تفزع اشرعني بعد اليوم فأني ، إني اخبركم } \\
& \text { إن نف } \\
& \text { سي الريـ }
\end{aligned}
$$

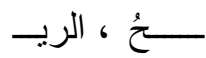

$$
\begin{aligned}
& \text { ₹ } \\
& \text { الر } \\
& \text { يح." (') }
\end{aligned}
$$

إن الثـاعر في قصيدته هذه عوّل كثيراً على تقنية البعثرة النصية، فهو يوظفها بشكل كبير في نصسه ليجعل

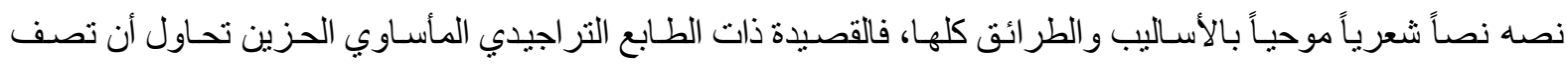

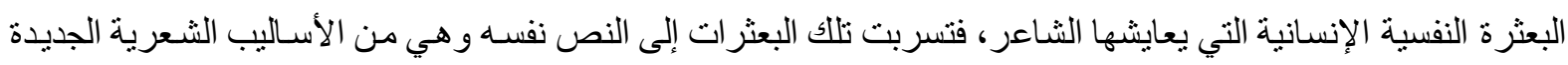

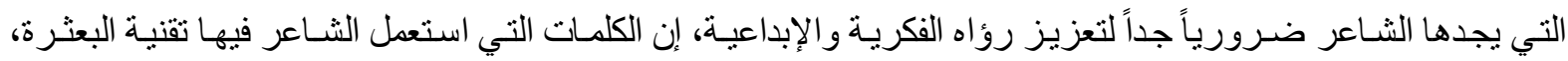
كلمات موحيـة جداً وذات أبعاد تعبيريـة كبيرة، إذا مـا استعمل فيها البعثرة (العـالم، الكلمـات، أسماك، مـاء، سيول، إنسـان،

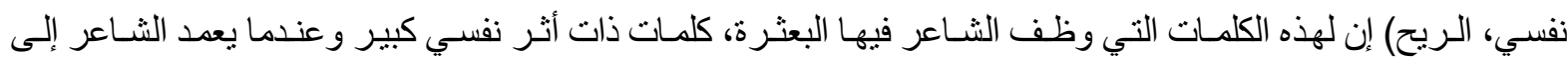

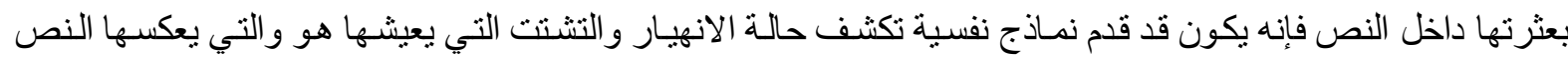

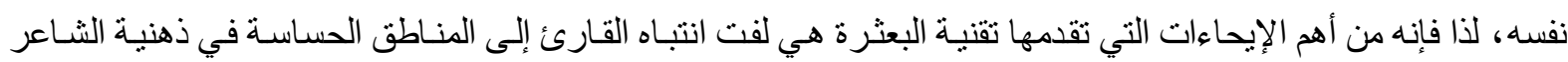
وفكره، عندما يشير صر احةً إلى مناطق الضعف والانكسار.

وثمـة قصـائد أخر للعزاوي تسير في الاتجـاه ذاته مـن التثكيل والبنـاء إذ يعدد أساسـاً إلى تقنيـة البعثرة في

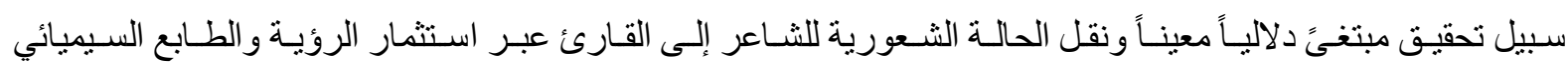
للقصيدة، ومن ذلك قصيدة ( حلم بدون كافيار):

$$
\text { لصيادي الأخطاء النحوية الحرب مؤتمر }
$$

للقصيدة الني تحجل فوق البلاطات

$$
\text { للعشق و المذاهب }
$$

ولكن بدون منافسة شريرة.

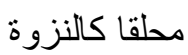




$$
\begin{aligned}
& \text { ب سيّى } \\
& \text { g } \\
& \varepsilon \\
& \text { اسمع جلبة الموت الابيض } \\
& \text { في فهرست الجسد"( (') }
\end{aligned}
$$

إن العز اوي يسعى في هذا النص إلى تأكيد العامل البنائي للقصيدة ودوره الفاعل في استنتاج، مـا يختبئ

من مضـامين دلاليـة وفكريـة ور اء الحروف و الترسيمات الأيقونيـة للنص، إن الثـاعر أكد في هذه القصبدة أن للبعثرة الحرفية إمكانية فاعلة في تدعيم رؤى النص و اتجاهاته الدالية، فـ "التقطيع شكل من الأشكال التي تحمل دلالية بلاغيـة يحملها الشكل قبل أي شيء آخر ، وذلك ليمارس فعله وفاعليته في نفسية القارئ الذي تفيض نفسـه بالأسئلة عن سـر اختيار

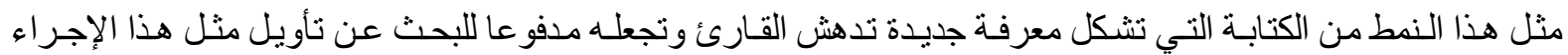
وتفسيره"(؟) فالشاعر يعبر عن كلمة (أسبوع) بشكل مبعثر كأنه يشعر بعظم الفترة التي يقتضيها نلك الدال الزمني، فهو يقف يبتكر إمكانية الزج بالأسلوب التعبيري الأمثل حتى يتمكن من إلباس القارئ اللباس النفسي الثـعري الخـاص الذي بني

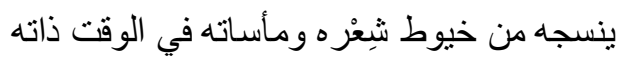

ويقف في قصيدته الأخرى (غربـة يوليسيس) ليجسد الطسابع نفسه في البنية و الأسلوب و الإمكانـات، فيجد

النثر و البعثرة طريقاً سالكاً نحو استلهام المشاعر لدى القارئ والتفاعل معها:

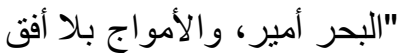
تنأى ، وسفينتهم دون ظلال

$$
\text { تغرت }
$$

هذا القول الثعري يشتخل على النجاح بمحاولة أخرى من محاو لات التعبير الثعري؛ وهي أن يقدم الثـاعر

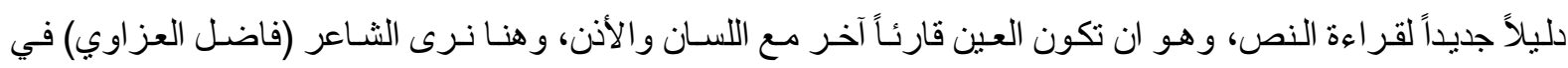

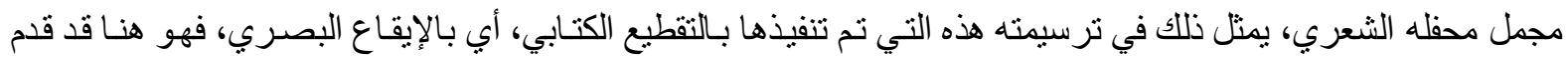
مو نتاجاً كتابياً بقوله: رق

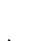

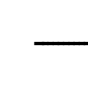

وهنـا نـرى التمثيل الصـوري البـائن مـن آليـة الكتابــة التـي اعتمــت تقطيع فعل الغـرق (تغـرق) بهـذه الصـورة

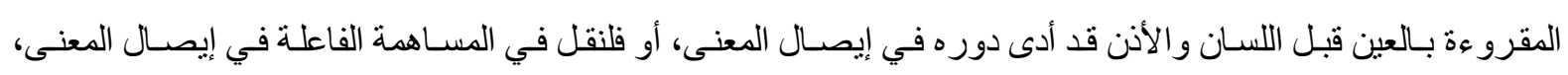


ذلك لأن تقطيع الفعل (أغرق) بهذه الطريقة يشعر القـارئ__عملياً _ـبحركة نزول السفينة التي تمر بمرحلة الغرق، إذ

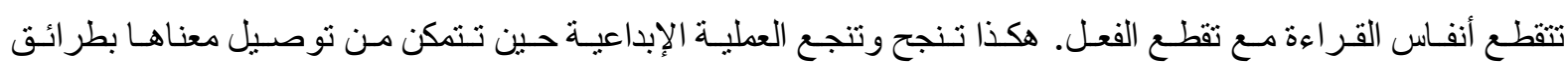
مبتكرة،"ولذللك لا يمكن للمتلقي أن يستكنه النص ويغور في داخله مـا لم يتمثل كلية صورته الطباعة ذلك أن جملة أنسـاقه

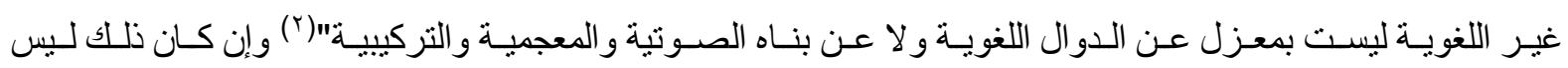
بالمستغرب على شاعر منل العزاوي قد عُرف بالابتكار في صناعة المعنى.

الفاتهة

اتضـح من خـلال البحث ان القصـيدة البصـرية تتعدد كيفياتهـا في نصـوص النــاعر فاضـل العزاوي، لإيمانـهـ

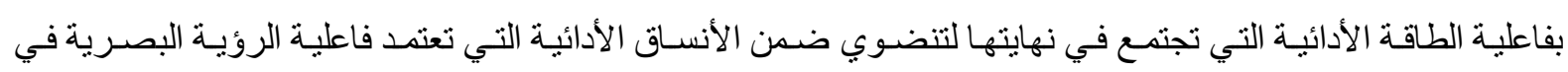

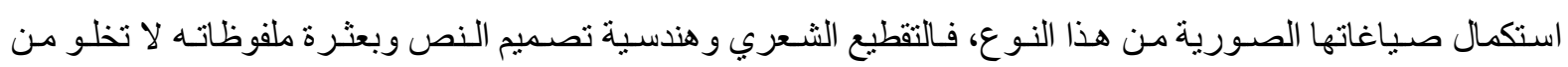

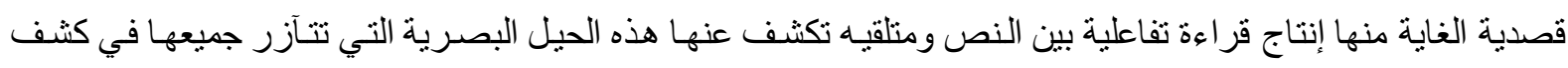
مقاصد الثـاعر ، فهي تنفتح بشكل يزود ملفوظـات النص بشحنة قرائية على وفق أعراف هذا التصوير التي تجعل هذه الأساليب تتشح بالشعرية التي تتطلب تفاعل المشاركة بين النص ومتلقيه ضمن تو اتر قرائي ممتع. فنظام القصيدة المرئية

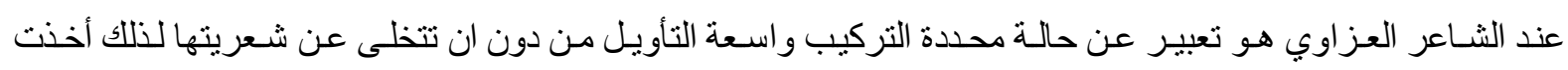

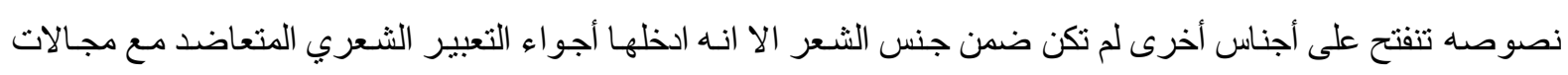

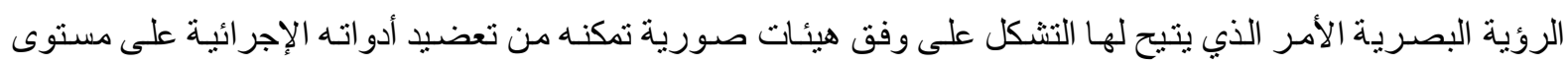

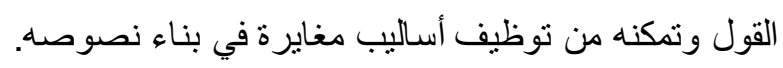

هوامش البمث

(') ينظر : الصورة الثعرية في النقد العربي الحديث، د. بشرى موسى صالح:؟؟. بن (r)

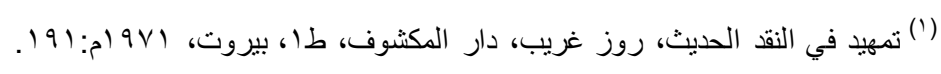

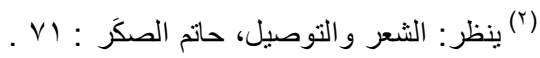

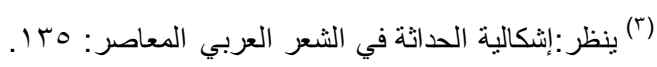

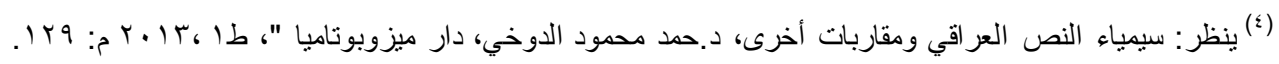

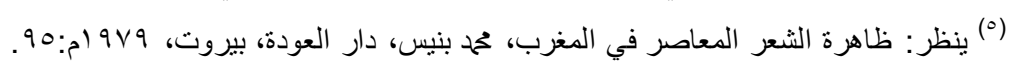

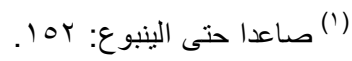

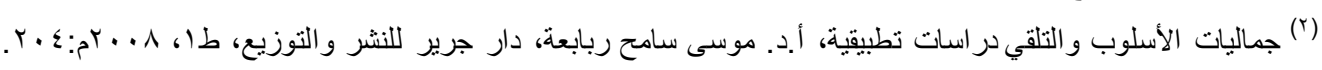

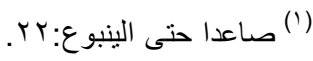

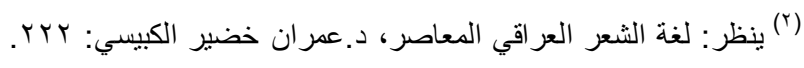

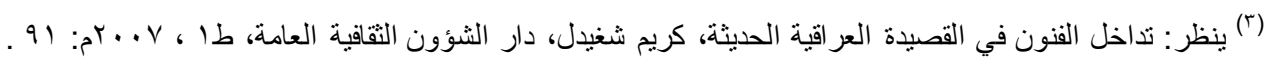

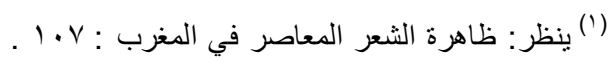

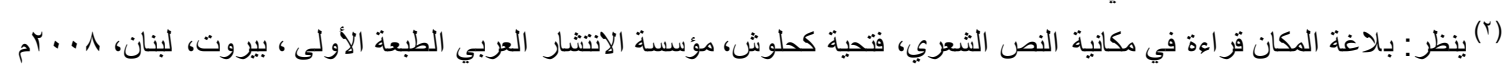
صמז (') صاعدا حتى الينبوع: • (1)

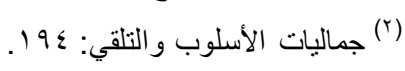

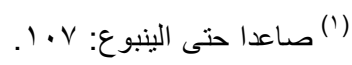




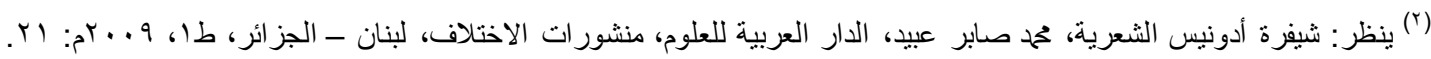

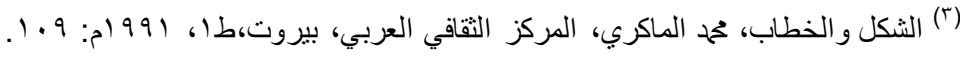

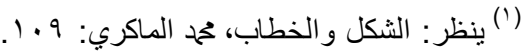
. صاعدا حتى الينبوع:r)

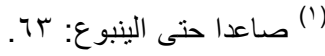

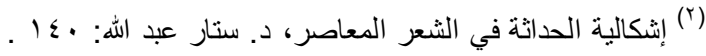

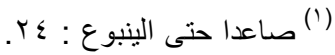
(؟) ينظر : الشعر والتلقي، علي جعفر العلاق، دراسات نقدية، دار الشروق، عمان، الأردن، طا، لو99 ام:70.

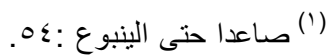

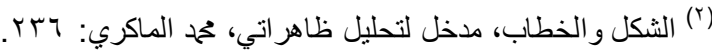

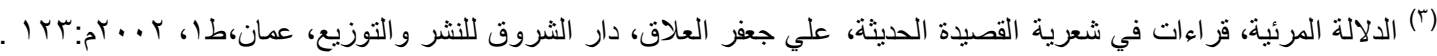

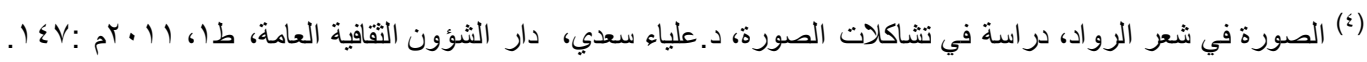

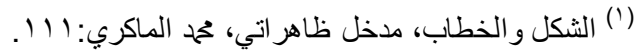

17 : 17 : (1) .l V^ : صاعدا حتى الينبوع : (1)

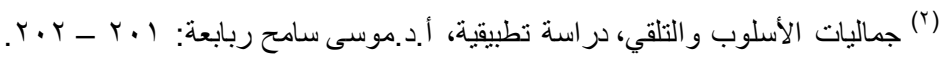
Yr) (ז) الخطاب الثعري من اللغوي إلى التشكيل البصري، رضا بن حميد، مجلة فصول، المجلد الخامس عشر، العدد الثاني، لو99 ام: 1 ـ1.

• إثكالية الحداثة في الثعر المعاصر، د. ستار عبد الله، دار رند للطباعة والنشر و التوزيع، دمشق، طا، ـ 1 بام.

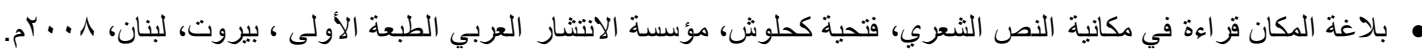

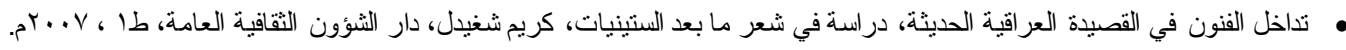

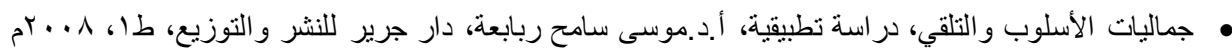

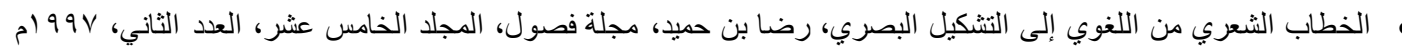

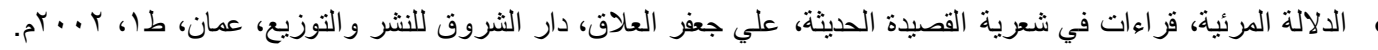

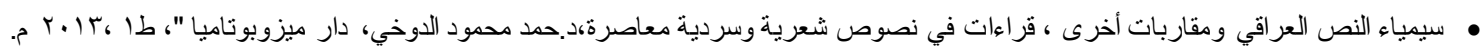

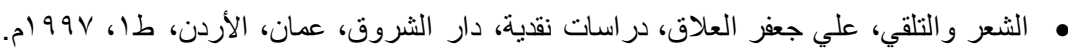

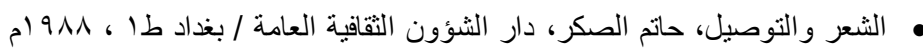

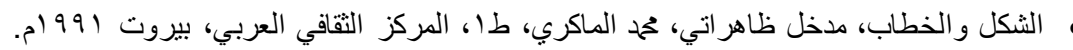

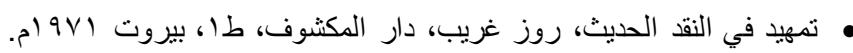

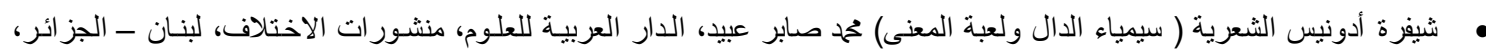

• الصورة الثعرية في النقد العربي الحديث، د. بشرى موسى صالح، الدار البيضاء/ المغرب، المركز الثقافي العربي، ؟99 ام.

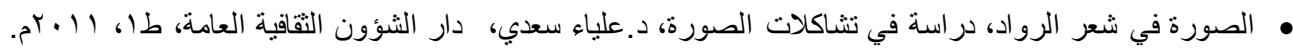

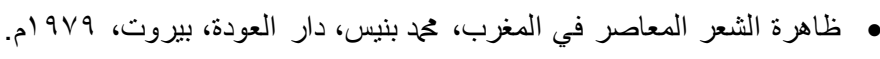

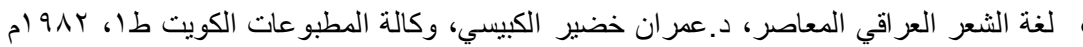

